\title{
THERMAL PERFORMANCE ANALYSIS OF SABUNKARAN RESIDENTIAL BUILDING TYPOLOGY
}

\author{
${ }^{1}$ Chro Hama RADHA, ${ }^{2}$ Istvan KISTELEGDI \\ ${ }^{1}$ Breuer Marcell Doctoral School, Institute of Architecture, Faculty of Engineering and \\ Information Technology, University of Pécs, Boszorkány u. 2, H-7624 Pécs, Hungary \\ e-mail:chroalih18@rocketmail.com \\ ${ }^{2}$ Department of Building Structures and Energy Design, Faculty of Engineering and \\ Information Technology, University of Pécs, Boszorkány u. 2, H-7624 Pécs, Hungary \\ e-mail: energiadesign@pmmik.pte.hu
}

Received 25 December 2016; accepted 20 March 2017

\begin{abstract}
Creating typology is a comparative method to investigate the physical or other characteristics of the built environment. It can be a useful instrument to facilitate the thermal performance assessment of existing buildings. Heat material's resistance and construction techniques play a significant role in energy performance of buildings. It is influenced by many factors, such as ambient weather conditions, building structure, and heating, ventilation and airconditioning systems.

The study was focused on analyzing five types of residential buildings at the center of the Sulaimani city (north of Iraq) to assess the energy performance of the building types and comparing results with dynamic analyses, using IDA ICE 4.7.1 software. The results revealed that the thermal performance of the buildings is mostly influenced by the variations in the construction techniques and materials.
\end{abstract}

Keywords: Building typology, Thermal performance, Building simulation

\section{Introduction}

Typology is the comparative study of physical or other characteristics of the built environment. It is also a way of thinking that does not refer to the age but to the place. As Frank and Schneekloth says 'types and ways of typing are used to produce and reproduce the material world and to give meaning to our place in it' [1]. The term building typology describes a classification of buildings according to some specific characteristic, which are related to the building thermal or energy performance [2]. The thermal performance of the building refers to the process of modeling the energy transfer between a building and its surroundings [3]. A modeling of the building energy 
performance and a sensitivity analysis of the different aspects affecting the building energy behavior are necessary to optimize the building's energy design or perform an energy audit [4].

The residential building sector is the first largest energy consumer. According to the annual report of the Kurdistan Ministry of Electricity and Energy (KMEE), 70\% of the total energy consumption is generated by the residential building sector. To improve the environmental performance of building it is essential to involve all parameters which control its energy efficiency [5]. The most effective methods to develop highly efficient, sustainable building systems is the research programs based energy simulation and monitoring of the building management systems, to be able to predict and minimize the total energy needs of the building [6].

\section{Energy consumption in Kurdistan}

In recent years, with the rapid development of urbanization, faster population growth, people's incomes and living standards, building energy consumption have increased dramatically especially in the residential buildings. Internationally, energy consumption of the residential sector accounts for $16-50 \%$ of that consumed by all sectors, and it averages approximately 30\% worldwide [7]. While the residential building sector accounts $70 \%$ of the total energy consumption in Kurdistan as it is shown in Fig. 1. Therefore, the energy consumption management is a very significant problem not only to take the losses resulting from increasing consumption patterns, but also to improve the performance of building energy systems [8].

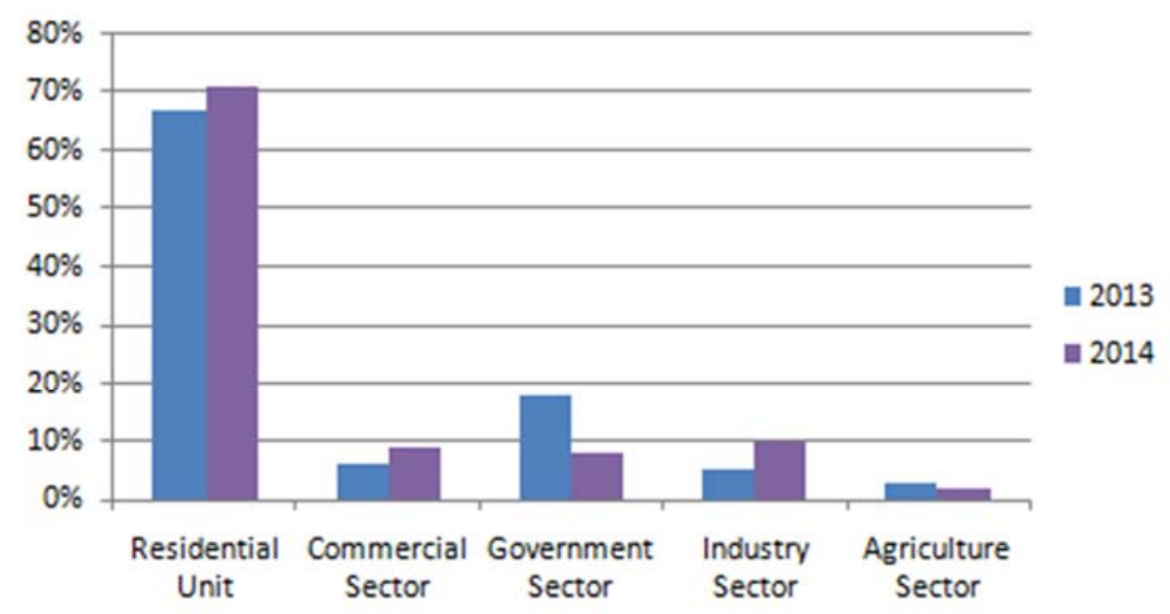

Fig. 1. Energy consumption by end use of Kurdistan, on the basis of [9] 


\subsection{Energy consumption in Sulaimani}

According to the annual report of the KMEE, in 2014 the electricity consumption for acclimatization and lighting residential buildings in Sulaimani was $71 \%$ of the total national generated electricity as it is shown in Fig. 2, [9].

Residential buildings in Sulaimani are constructed in a single-family detached house, single-family terraced house and apartment blocks form as it is shown in Fig. 3.

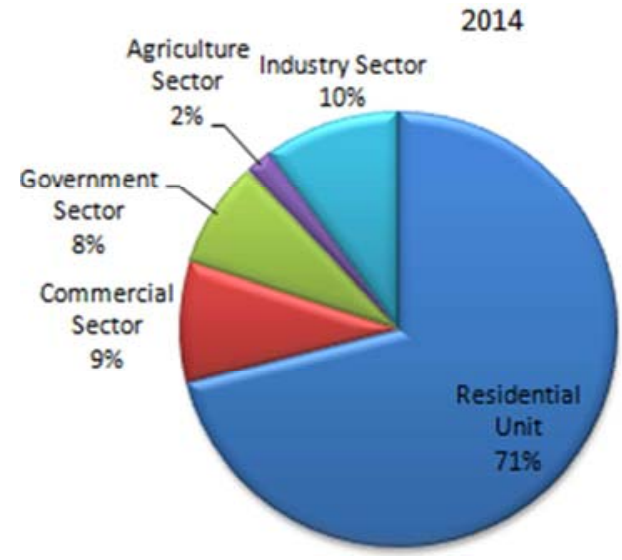

Fig. 2. Energy consumption by end use of Sulaimani, on the basis of [9]

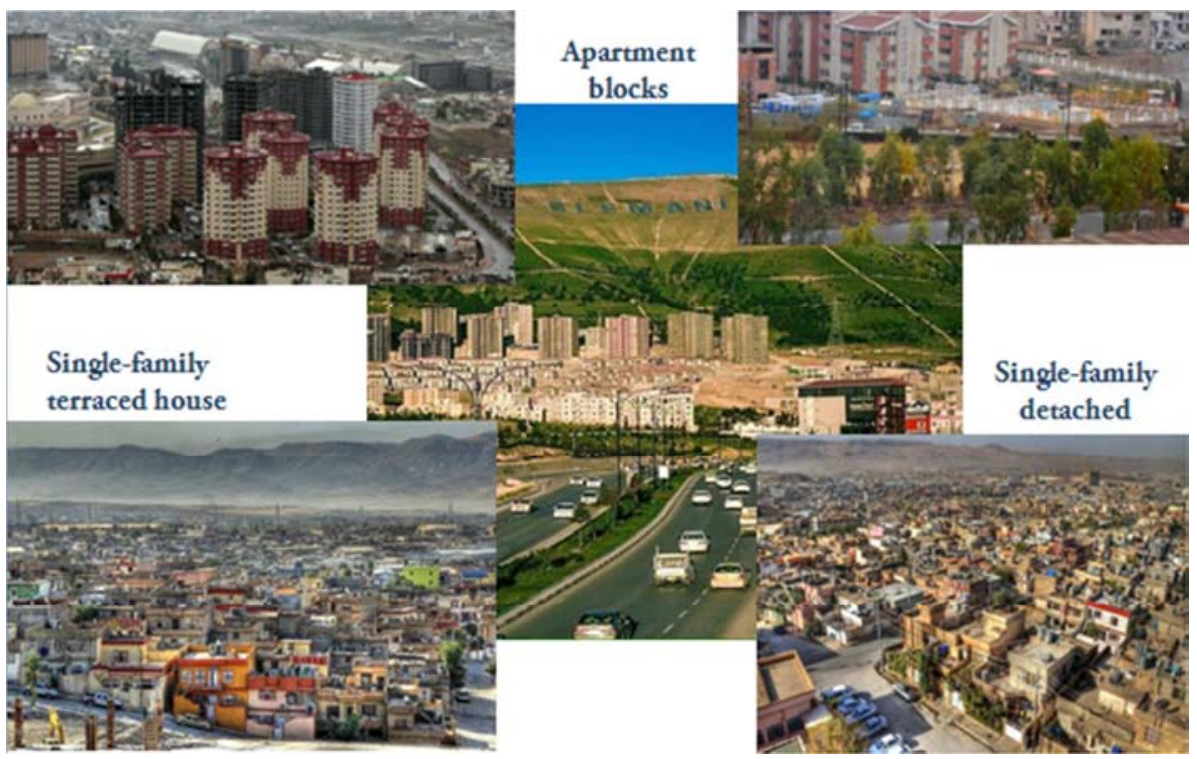

Fig. 3. Examples of Residential Buildings in Sulaimani 


\subsection{Residential household energy consumption}

It is important to present an anatomy of energy end-uses in the residential buildings, to assess the energy performance analysis, while this information is not available in Kurdistan. Therefore, this study evaluated a middle-income urban residential community in Kurdistan.

Fig. 4 shows the greatest user of energy in residential buildings is for cooling (electricity). The second largest use is for heating (electricity) followed by domestic hot water (electricity), plug loads, and other uses. 58\% of the consumed energy stands for indoor air conditioning (heating and cooling).

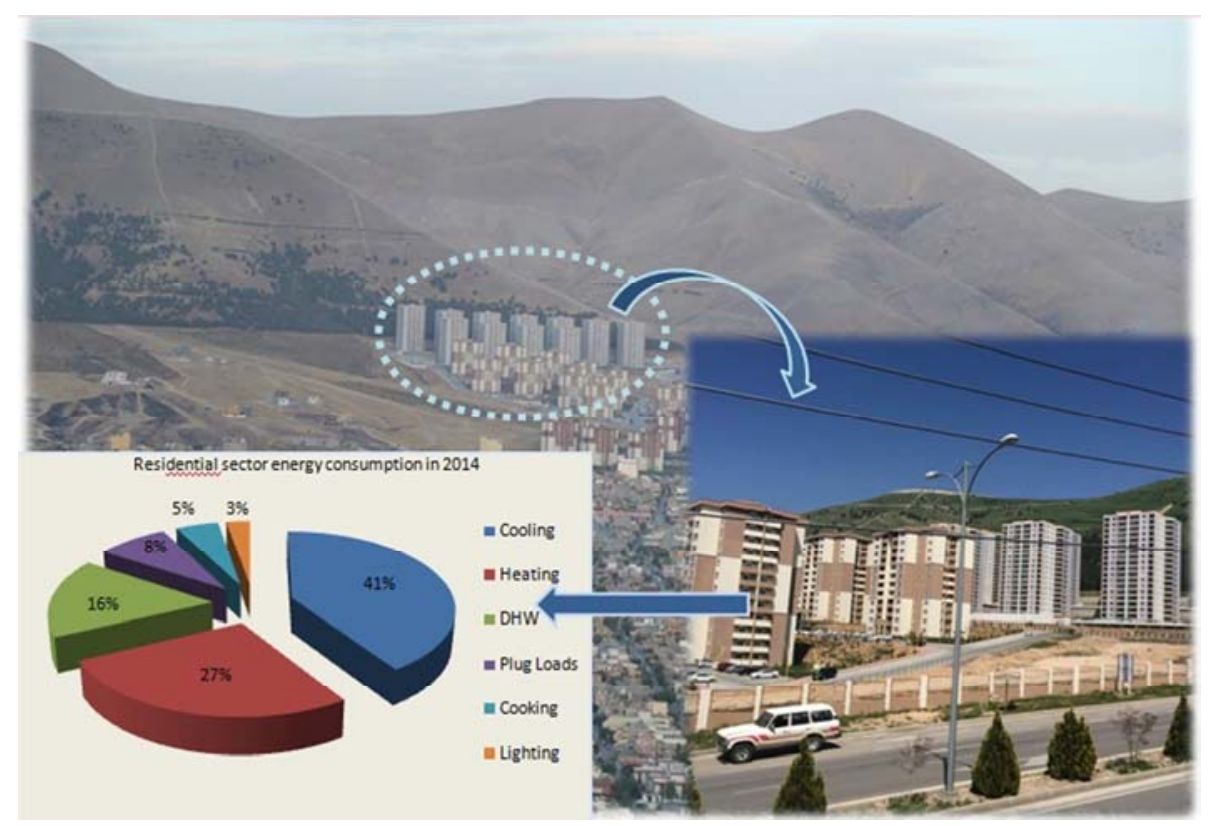

Fig. 4. Energy Consumption per Household in Goizha city, Sulaimani

\section{Residential building types in Sabunkaran}

In average, $98 \%$ of the world's building stock consists of existing buildings [10]. In addition, the study of the existing building types of a certain period reflects the life of this community and gives its urban image. This image is determined by civilization factors in terms of cultural, geographical, social, technical, political and economic indicators. All these indicators contribute to giving qualities and properties and relations for housing patterns within a particular community [11]. From this point, the study classifies the residential building types in Sabunkaran, which located in the center of Sulaimani city that took place through a field survey that was done by the researcher on the existing house's buildings within the study area. Five types were identified as it is 
shown in Fig. 5 and is analyzed based on their morphological and compositional properties.

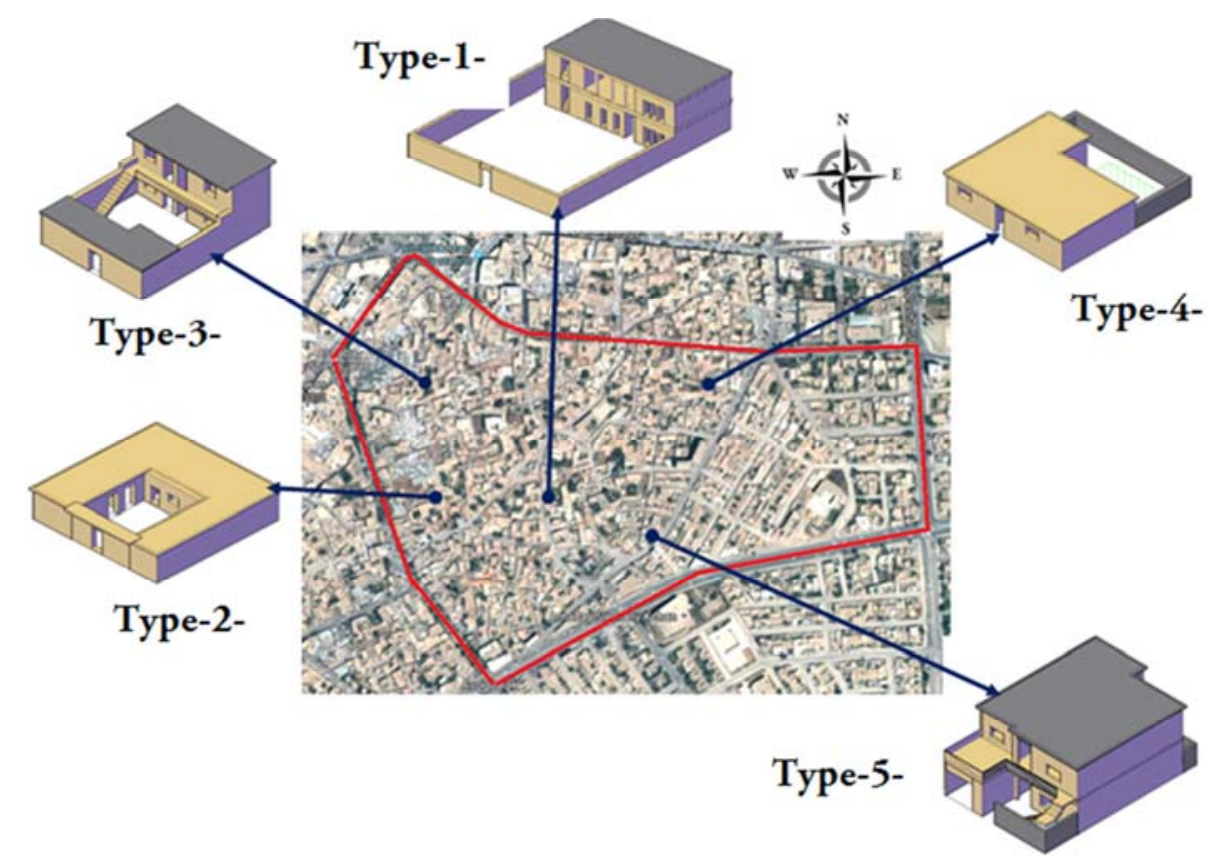

Fig. 5. Residential building types in Sabunkaran

\subsection{Morphological properties of residential buildings}

Morphological properties include analyzing building materials, wall thickness, building orientation, window and opening size, entrance and access to the house, and land plot size.

Mostly, Type 1 is the traditional residential buildings in Sabunkaran. It consists of two floors; it has characterized by an open front big patio. According to the built materials, clay brick is used as a wall built with a thickness ranged between $(40-80) \mathrm{cm}$, mud or clay is used for the interior and external wall finishing. While the house roofing was made of boles of trees, which diameters not exceed than $15 \mathrm{~cm}$ - it was used as the form of cross-beams, which covered by a layer of mat, then placed a layer of compressed soil with a thickness $20 \mathrm{~cm}$ on it [12]. Furthermore, building oriented toward the inside, and the size of the land plot ranged from a medium to large, as it is shown in Fig. 6.

The Type 2 is semi-traditional buildings, mostly resembling the type one in terms of walls and roof construction materials, the size of the opening and the window. It differs from the first type in the size of the land plot that ranges from medium to small, and it is characterized by the central courtyard, as it is shown in Fig. 7. 

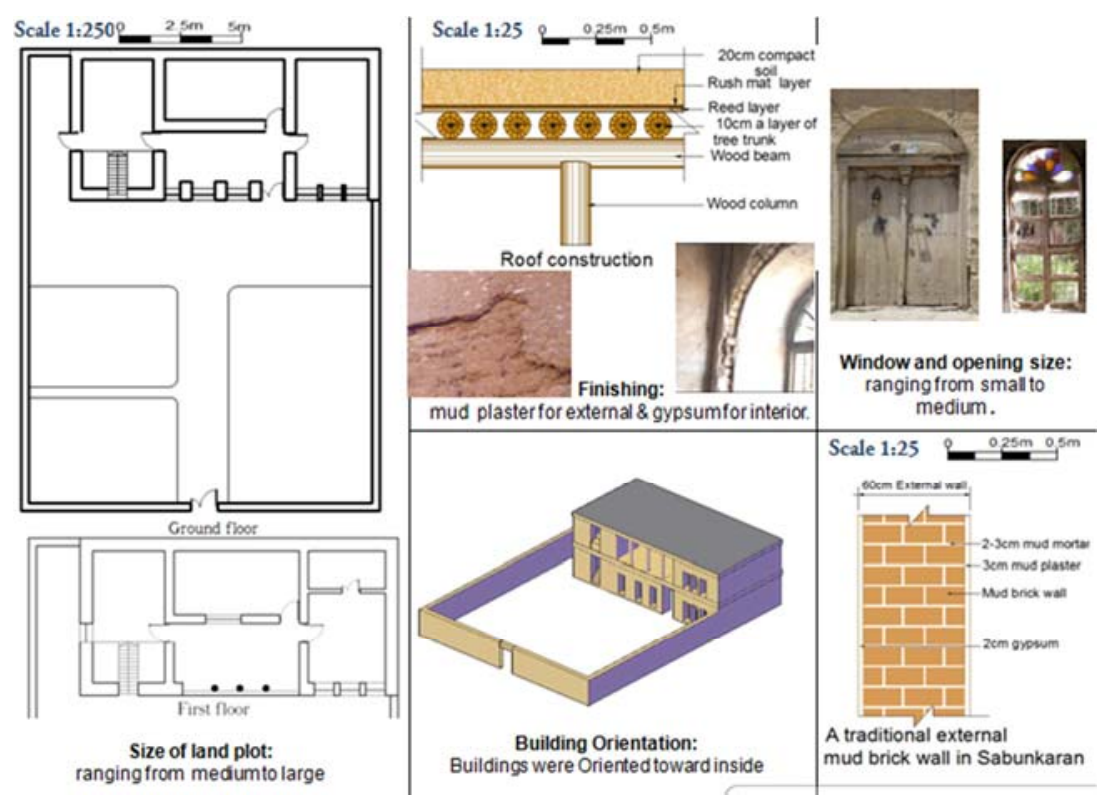

Fig. 6. The Morphology properties of Type-1

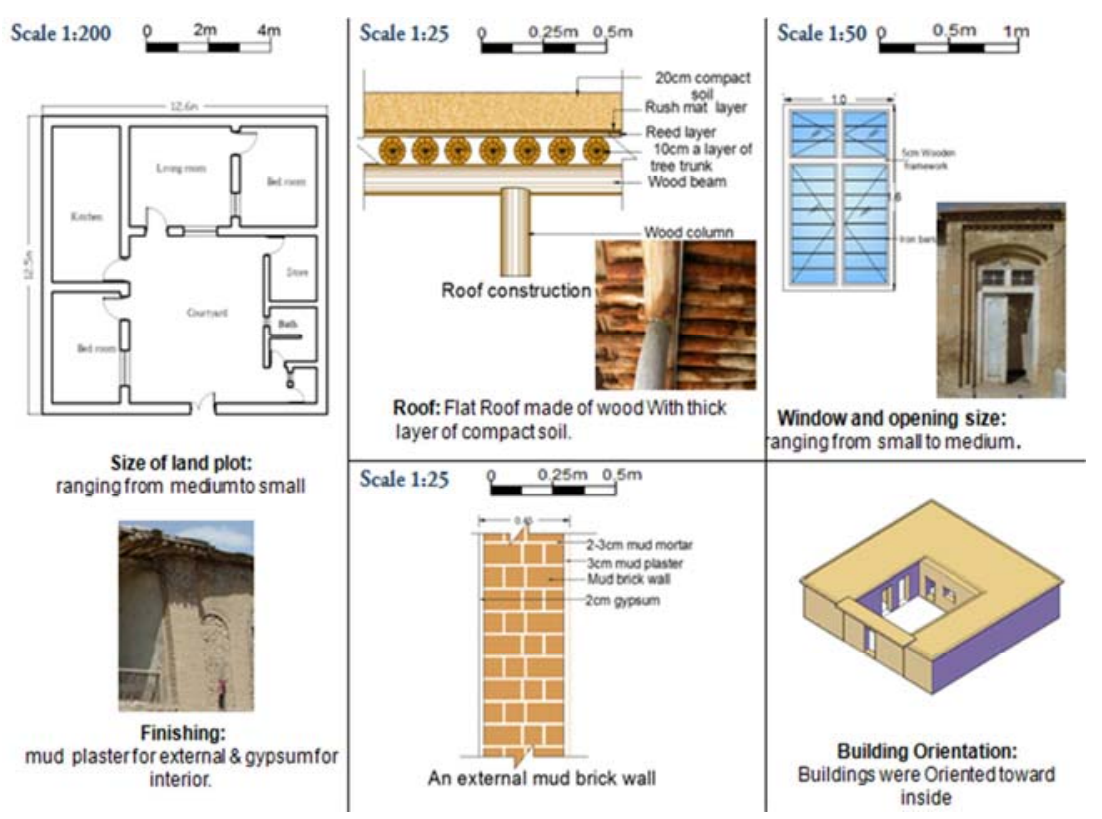

Fig. 7. The Morphology properties of Type-2 
While Type 3 usually consists of two stores, the main characteristic is the use of local stone beside the mud-brick and sometimes was used together, especially at the entrance of the building. In addition, the size of the openings was increased, in comparison with the previous types. However, the spaces oriented toward inside around the central courtyard, as it is shown in Fig. 8.

The main feature that distinguishes Type 4 with other previous types is the use of reinforced concrete for roofing the buildings. In addition, stone and bricks were used together without external finishing, mostly the building oriented towards inside through the back yard and toward outside through small windows across the facade at the height $1.5 \mathrm{~m}$ as it is shown in Fig. 9.

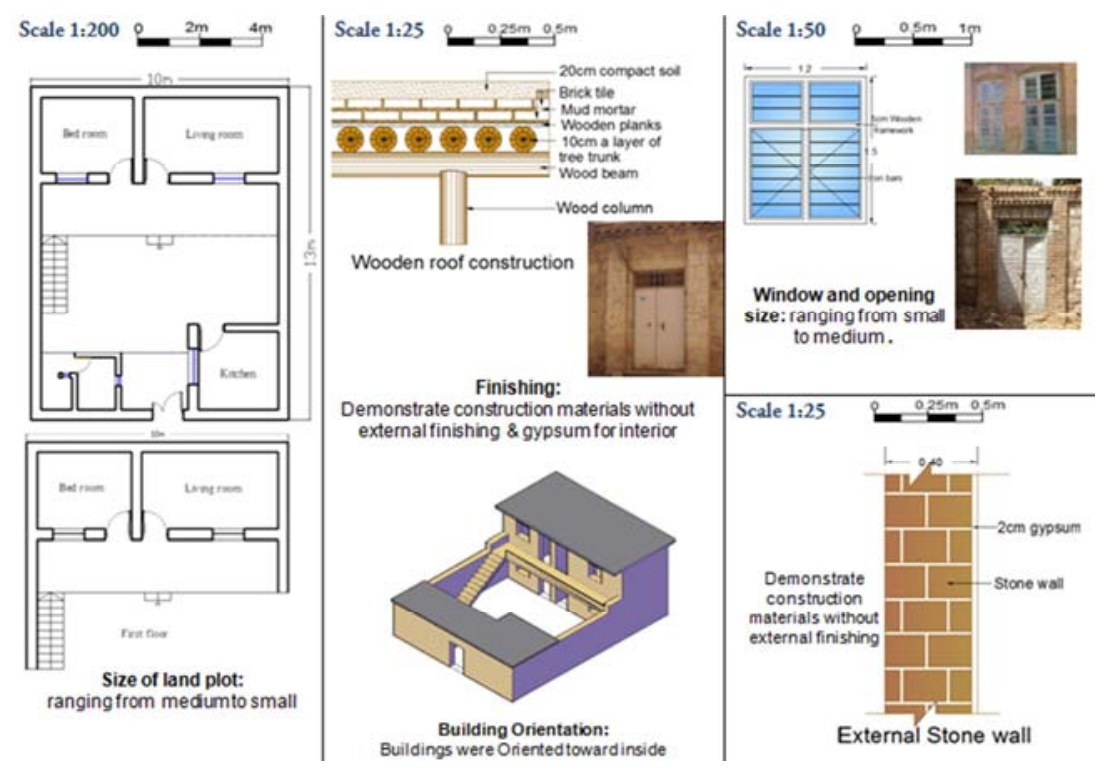

Fig. 8. The Morphology properties of Type-3

Type 5 is tending to modern houses as it is shown in Fig. 10 is characterized by a front small yard and consists of two floors, In addition; it has two entrances; the small one leads to the house's space while the big entrance leads to the garage. The hollow cement blocks were used for constructing external and internal walls of a thickness $20 \mathrm{~cm}$ and roofing the house of reinforced concrete with a thickness $15 \mathrm{~cm} \mathrm{[12].}$

\subsection{Compositional properties of residential buildings}

Compositional properties of a space organization are characterized by the open space dominance over the building mass, as in the first type. In addition, there is a balance between mass and space, as in Type 2, Type 3. However, in the Type 4 and Type 5, the building mass is dominant on the open space. 

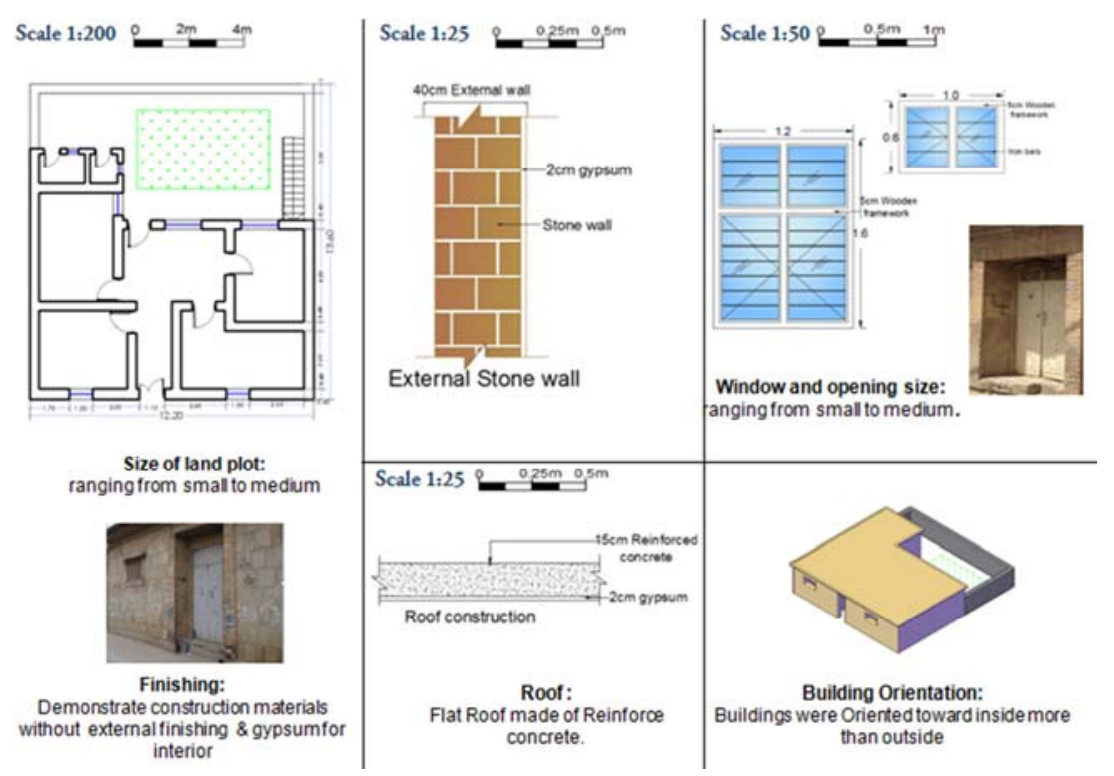

Fig. 9. The morphology properties of Type -4

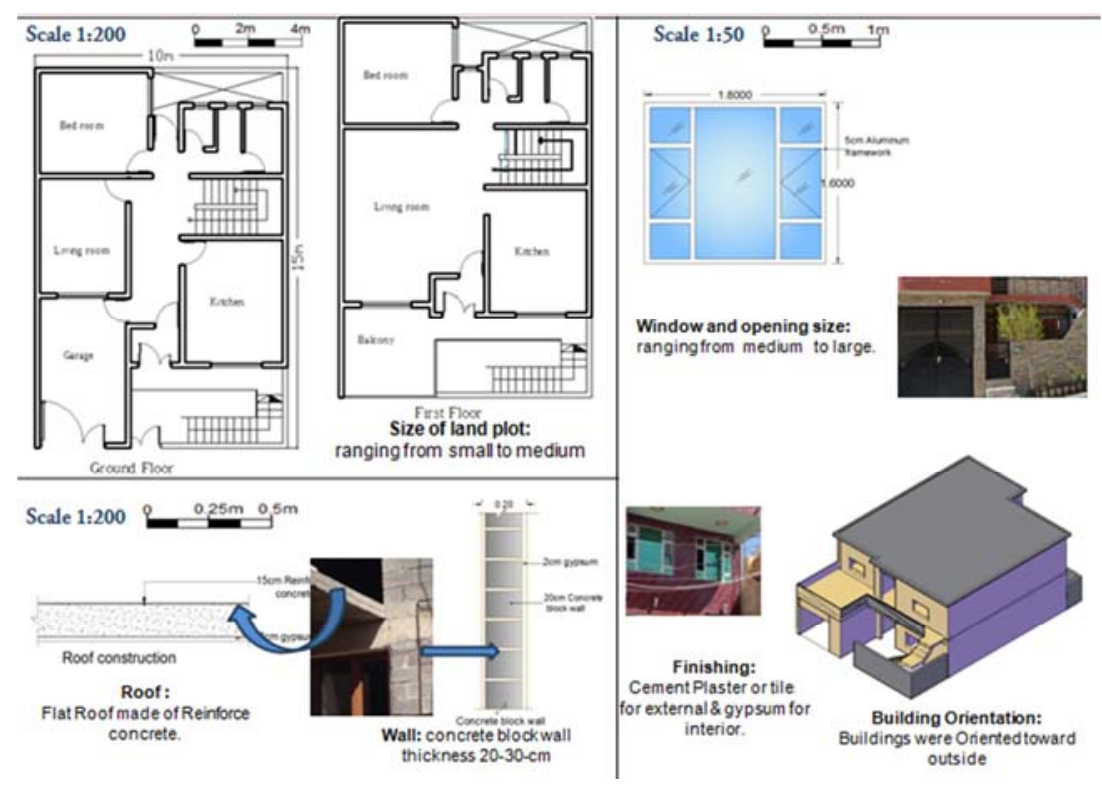

Fig. 10. The Morphology properties of Type -5

According to space organization, there was overlapping between spaces and functions, as in Type 1, Type 2. While in Type 3 began to separate service function with the other functions, it is an indicator to the beginning of the transformation of the space 
organization. In addition, in the Type 4, Type 5 giving more privacy for space functions, and separate spaces based on their function.

Through in Fig. 6-Fig. 10 it can be observed that the morphological and compositional characteristics are changed progressively. This is the nature of the change in the characteristics of residential constructions in many communities despite their different cultures.

\section{Methodology}

For the purpose of assessing the energy performance of the residential building types, there is a need for accurate calculation and modeling tools. The methodology uses the Indoor Climate and IDA ICE 4.7.1 software, with integrated measurement data, made on the Sulaimani Meteorology Authority (SMA) at the height of $10 \mathrm{~m}$ from ground level [13].

The objects being analyzed and compared are five types of residential buildings in Sabunkaran (Sulaimani city center), by assuming the same orientation and weather data in a whole year period in 2014, where the building materials and construction techniques are variable.

\section{Energy performance analysis of the typologies}

The analyzing of five types of residential building's energy performance by the dynamic building physics model using IDA ICE 4.7.1 software is done as it is shown in Fig. 11.

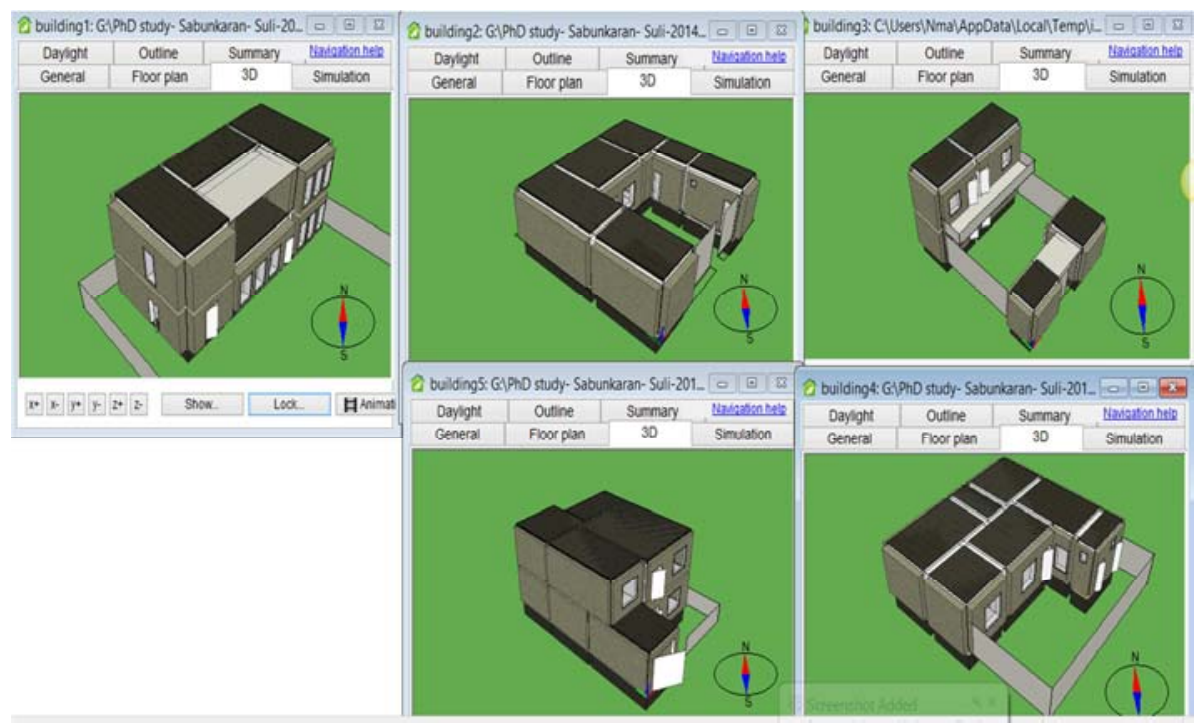

Fig. 11. IDA ICE computational models for residential building types 
After simulation the models and comparative results from IDA ICE by comparing the total energy for each type as it is in shown in Table I, it can be concluded:

- The best residential building type in terms of energy-efficiency performance is type two;

- $\quad$ The type one performed as the second best model;

- There is a similarity between type three and four in terms of energy efficiency;

- Type five is the largest energy consumer, and it was considered the worst type.

\section{Table I}

Total supplied energy report of the models from IDA ICE

\begin{tabular}{|c|c|c|c|c|c|c|c|c|c|c|}
\hline & \multicolumn{2}{|c|}{ building1 } & \multicolumn{2}{|c|}{ building2 } & \multicolumn{2}{|c|}{ building3 } & \multicolumn{2}{|c|}{ building4 } & \multicolumn{2}{|c|}{ building 5} \\
\hline & $\sum_{\underline{y}}^{F}$ & $\sum_{\underline{y}}^{\mathfrak{E}}$ & $\sum_{y}^{5}$ & $\sum_{\underline{E}}^{\mathcal{E}}$ & $\sum_{\underline{y}}^{5}$ & $\sum_{\underline{\Sigma}}^{\mathcal{E}}$ & $\sum_{i}^{E}$ & 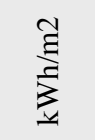 & $\sum_{i}^{5}$ & $\sum_{\underline{E}}^{\mathfrak{E}}$ \\
\hline $\begin{array}{l}\text { Lighting, } \\
\text { facility }\end{array}$ & 1839 & 11.6 & 920 & 11.5 & 1051 & 15.5 & 1051 & 13.4 & 2234 & 11.2 \\
\hline $\begin{array}{l}\text { Electric } \\
\text { cooling }\end{array}$ & 5949 & 37.6 & 2074 & 25.9 & 3729 & 55.0 & 4525 & 57.8 & 7968 & 39.8 \\
\hline HVAC aux & 0 & 0.0 & 0 & 0.0 & 0 & 0.0 & 0 & 0.0 & 0 & 0.0 \\
\hline $\begin{array}{l}\text { Electric } \\
\text { heating }\end{array}$ & 8421 & 53.2 & 6516 & 81.3 & 6283 & 92.6 & 6597 & 84.2 & 8883 & 44.4 \\
\hline $\begin{array}{l}\text { Total, } \\
\text { Facility } \\
\text { electric }\end{array}$ & 16209 & 102.3 & 9510 & 118.6 & 11063 & 163.1 & 12173 & 155.4 & 19085 & 95.4 \\
\hline $\begin{array}{l}\text { Fuel } \\
\text { heating }\end{array}$ & 19508 & 123.2 & 14179 & 176.8 & 26568 & 391.6 & 28163 & 359.6 & 43182 & 215.8 \\
\hline $\begin{array}{l}\text { Total, } \\
\text { Facility } \\
\text { fuel* }\end{array}$ & 19508 & 123.2 & 14179 & 176.8 & 26568 & 391.6 & 28163 & 359.6 & 43182 & 215.8 \\
\hline Total & 35717 & 225.5 & 23689 & 295.4 & 37631 & 554.7 & 40336 & 515.1 & 62267 & 311.2 \\
\hline
\end{tabular}

By analyzing the supplied energy results as shown in Table $I$, it is evident that Type 1 of the residential building requires only $225.5 \mathrm{kWh} / \mathrm{m}^{2}$, while Type 2 requires $295.4 \mathrm{kWh} / \mathrm{m}^{2}$. Furthermore, Type 5, which is the largest energy consumer, and the worst type in terms of its energy performance, it required $311.2 \mathrm{kWh} / \mathrm{m}^{2}$. Both Type 3 and Type 4 required $554.7 \mathrm{kWh} / \mathrm{m}^{2}$ and $515.1 \mathrm{kWh} / \mathrm{m}^{2}$, respectively.

It is significant to note that IDA ICE software, for calculating supplied energy per meter square has used up the whole base area into account during the calculating's procedure. Furthermore, it has not been considered the fact, there are some spaces did not require heating, and cooling system included (bathrooms, storages, and garage), that gives inaccurate results. Thus, to find out the actual delivered energy per meter squared, 
the deduction of the space's area that does not require air-conditioning to the total area, when calculated in this manner, it runs out, that type one is actually the best among the others in terms of energy efficiency, which required only $225.5 \mathrm{kWh} / \mathrm{m}^{2}$. The worst type is type three, which required $606.95 \mathrm{kWh} / \mathrm{m}^{2}$ as it is shown in Table II. In addition, Fig. 12 shows the total supplied energy for real conditioning area (left), and the required delivered energy per $\mathrm{m}^{2}$ (right), for residential building typologies.

\section{Table II}

The various area and delivered energy in the building models

\begin{tabular}{|l|l|l|l|l|l|}
\hline & $\begin{array}{l}\text { Building } \\
\text { type-1- }\end{array}$ & $\begin{array}{l}\text { Building } \\
\text { type -2- }\end{array}$ & $\begin{array}{l}\text { Building } \\
\text { type -3- }\end{array}$ & $\begin{array}{l}\text { Building } \\
\text { type-4- }\end{array}$ & $\begin{array}{l}\text { Building } \\
\text { type-5- }\end{array}$ \\
\hline $\begin{array}{l}\text { Model floor area } \\
\left(\mathrm{m}^{2}\right)\end{array}$ & 158 & 80.2 & 67.8 & 78.3 & 200.1 \\
$\begin{array}{l}\text { Heated \& cooled } \\
\text { area }\left(\mathrm{m}^{2}\right)\end{array}$ & 158 & 66.24 & 62 & 73.9 & 155.6 \\
$\begin{array}{l}\text { Delivered energy } \\
\left(\mathrm{kWh} / \mathrm{m}^{2}\right)\end{array}$ & 225.5 & 357.6 & 606.95 & 545.8 & 400.17 \\
$\begin{array}{l}\text { Total delivered } \\
\text { energy }(\mathrm{kWh})\end{array}$ & 35629 & 23687 & 37631 & 40335 & 62256 \\
\hline
\end{tabular}
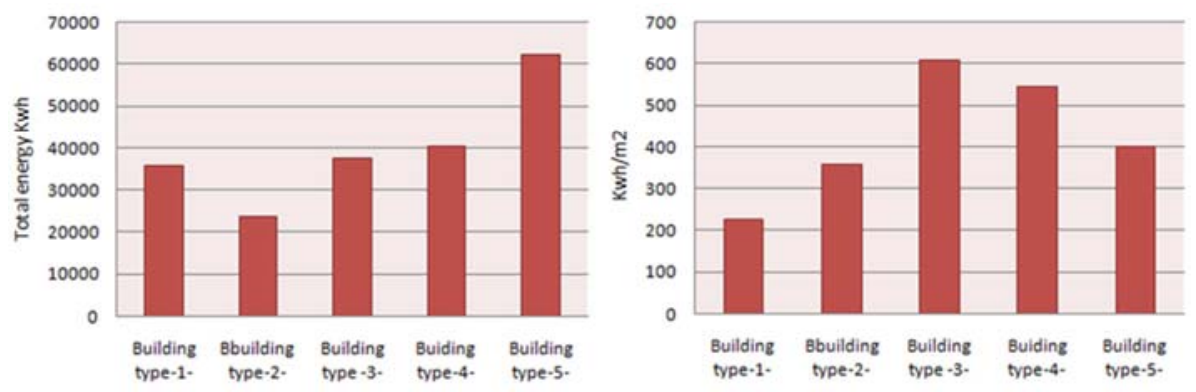

Fig. 12. The total supplied energy (left), the energy required per meter square (right), in the building types

\section{Conclusions}

The results revealed that the morphologies and compositional attributes of the buildings have a significant influence on the thermal and energy performance. In addition, the size and the volume of the built area also play a big role of energy consumption.

In summation, the building materials and construction techniques also have a substantial part in the energy performance. Thus, the houses that have better thermal mass, they deliver lower energy requirement. 


\section{Acknowledgements}

The Author would like to thank her supervisor's research Professor Dr. Istvan Kistelegdi, senior lecturer at the Institute of Architecture, Department of Building Structures and Energy Design, Faculty of Engineering and Information Technology, University of Pécs, for his help and support.

\section{References}

[1] Guney Y. I. Type and typology in architectural discourse, Department of Architecture, Faculty of Architecture and Engineering, Balıkesir University Turkey, BAU FBE Magn, Vol. 9, No. 1, 2007, pp. 3-18.

[2] Dascalaki E., Droutsa P. Typology approach for building stock energy assessment, National Scientific Report, Athens, Greece, May 2012, pp. 5-17.

[3] Joseph M., Jose V., Habeeb A. Thermal performance of buildings: Case study and experimental validation of educational building, International Journal of Advanced Research in Electrical, Electronics and Instrumentation Engineering, Vol. 4, No. 6, 2015, pp. 4968-4974.

[4] Ballarini I., Corrado V. A new thermal analysis by numerical simulation to investigate the energy performance of buildings, Proc. of 12th Conference of International Building Performance Simulation Association, Sydney, Australia, 14-16 November, 2011, pp. 2225-2232.

[5] Sharma R., Purohit D. G. M. Energy efficient facades for hot and dry climate in India, IJISET Journal, Vol. 1, No. 6, 2014, pp. 536-542.

[6] Kistelegdi I., Baranyai B. Energy management monitoring and control of public buildings, Pollack Periodica, Vol. 9, No. 2, 2014, pp. 77-88.

[7] Hassan S. A., Al-Ashwal T. N. The impact of building envelope modification on energy performance of high-rise apartments in Kuala Lumpur, Malaysia, International Transaction Journal of Engineering, Management, Applied Sciences and Technologies, Vol. 6 No. 3, 2015, pp. 91-105.

[8] Khosravani H., Castilla M., Berenguel M., Ruano A., Ferreira P. A comparison of energy consumption prediction models based on neural networks of a bioclimatic building, Energies, Vol. 9, No. 1, 2016, pp. 57-80.

[9] KMEE, Kurdistan Ministry of Electricity and Energy, Annual Report, Kurdistan Region, Iraq, 2014.

[10] Kovari G., Kistelegdi I. Optimized building automation and control for the improvement of energy efficiency and climate comfort of office buildings, Pollack Periodica, Vol. 10, No. 1, 2015, pp. 71-82.

[11] Ali H. A. The effect of cultural factors in the change of Dwelling types: Analytical study for changing the housing types in Sulaimani City, Ph.D. Thesis, College of Engineering, University of Sulaimani, Iraq, 2010, pp. 107-135.

[12] Radha C., Kistelegdi I. Efficient natural ventilation in traditional and contemporary houses in hot and dry climate, Proc. of 2nd International Conference on Architecture, Structure and Civil Engineering (ICASCE'16), London, UK, March 26-27, 2016, pp. 165-167.

[13] SMA, Sulaimani meteorological authority, Annual Report, Sulaimani, Kurdistan Region, Iraq, 2014. 